\title{
Allopregnanolone and neurogenesis in the nigrostriatal
}

\section{tract}

\section{Jun Ming Wang *}

Departments of Pathology, Psychiatry and Human Behavior, and Pharmacology and Toxicology, Memory Impairment and Neurodegenerative Dementia Center, University Mississippi Medical Center, Jackson, MS, USA

\section{Edited by:}

Giulia Puja, Università degli Studi di Modena e Reggio Emilia, Italy

Reviewed by:

Enzo Wanke, University

Milano-Bicocca, Italy

Patrizia Longone, Fondazione Santa Lucia, Italy

Giulia Puja, Università degli Studi di

Modena e Reggio Emilia, Italy

*Correspondence:

Jun Ming Wang, Department of

Pathology, University Mississippi

Medical Center, 2500 N State

Street, Jackson, MS 39216, USA

e-mail: jwang@umc.edu
Reinstalling the neurobiological circuits to effectively change the debilitating course of neurodegenerative diseases is of utmost importance. This reinstallation requires generation of new cells which are able to differentiate into specific types of neurons and modification of the local environment suitable for integration of these new neurons into the neuronal circuits. Allopregnanolone (AP $\alpha)$ seems to be involved in both of these processes, and therefore, is a potential neurotrophic agent. Loss of dopamine neurons in the substantia nigra (SN) is one of the main pathological features of Parkinson's and also in, at least, a subset of Alzheimer's patients. Therefore, reinstallation of the dopamine neurons in nigrostriatal tract is of unique importance for these neurodegenerative diseases. However, for the neurogenic status and the roles of allopregnanolone in the nigrostriatal tract, the evidence is accumulating and debating. This review summarizes recent studies regarding the neurogenic status in the nigrostriatal tract. Furthermore, special attention is placed on evidence suggesting that reductions in allopregnenalone levels are one of the major pathological features in PD and AD. This evidence has also been confirmed in brains of mice that were lesioned with 1-methyl-4-phenyl-1,2,3,6-tetrahydropyridine (MPTP) or those bearing neurodegenerative mutations. Lastly, we highlight studies showing that allopregnanalone can augment the number of total cells and dopaminergic neurons via peripheral exogenous administration.

Keywords: allopregnanolone, neurogenesis, substantia nigra, nigrostriatal, tyrosine hydoxylase, neural circuits motor performance

\section{INTRODUCTION}

Research data consistently suggests that a small molecule, the neurosteroid allopregnanolone $(\mathrm{AP} \alpha)$ capable of permeating the brain-blood-barrier, is a latent restorative therapeutic agent for reestablishing neuronal circuits in hippocampus and also the nigrostrital tract. Supportive data demonstrated that AP $\alpha$ functioned as a neurotrophic factor for human, rat, and mouse neural progenitor cells (Keller et al., 2004; Wang et al., 2005, 2010; Charalampopoulos et al., 2008) and augmented the number of cells in the hippocampus and reversed deficits in learning and memory in a mouse model for Alzheimer's disease (3xTgAD, a triple transgenic with APPSwe, PS1M146V, tauP301L) (Wang et al., 2010; Chen et al., 2011; Singh et al., 2012), for review see Brinton (2013) and Irwin and Brinton (2014). In contrast, $\mathrm{AP} \alpha$ has been reported to inhibit the learning and memory when chronically treated for 3 months (Bengtsson et al., 2012, 2013) and the potential mechanisms for this discrepancy have been discussed elsewhere (Brinton, 2013; Wang, 2013; Irwin and Brinton, 2014). In addition, $\mathrm{AP} \alpha$ also plays a role in regulating depressive episodes (Schüle et al., 2011, 2014; Evans et al., 2012; Hellgren et al., 2014) and the antidepressant effects of $\mathrm{AP} \alpha$ is probably mediated via neurogenesis in dentate gyrus in hippocampus (Evans et al., 2012). Recently, accumulated data indicated that $\mathrm{AP} \alpha$ increased the number of total cells, tyrosine hydroxylase (TH) positive cells, and newly formed (BrdU positive) TH expressing cells in the substantia nigra (SN), and improved the balance and coordination of 1-methyl4-phenyl-1,2,3,6-tetrahydropyridine (MPTP)-lesioned mice, an animal model for Parkinson's disease (PD; Adeosun et al., 2012). The augmentation of $\mathrm{TH}$ positive neurons by $\mathrm{AP} \alpha$ in the $\mathrm{SN}$ of 3xTgAD mice (Sun et al., 2012a) clarified that AP $\alpha$ accomplished its role through the reestablishment of DA neuronal architecture, rather than blockading the neurotoxic effects of MPTP. This review summarizes and highlights the current discoveries involving the generation of new neurons in the nigrostriatal tract and the therapeutic potential for the related neuronal disorders of $\mathrm{AP} \alpha$.

\section{THE SIGNIFICANCE FOR A THERAPEUTIC STRATEGY TO REINSTALL THE FUNCTIONAL DA NEURONS IN NIGROSTRIATAL TRACT}

$\mathrm{AD}$ and PD are devastating, degenerating neural disorders which currently cannot be cured. More than 5 million and nearly 1 million Americans have $\mathrm{AD}$ or $\mathrm{PD}$, respectively, and every minute a new case is added in this cohort. These diseases not only bring about suffering for the patients themselves, it is 
also a heavy financial burden and high labor cost for both the families and society. The severity of these diseases is closely related to the number of neurons that are lost in specific brain regions.

For example, the symptoms of PD are closely associated with the depletion of striatal dopamine (DA), brought on by the impairment of normal neurobiological architecture of neural cells in the nigrostriatal tract, resulting in the degeneration and death of DA neurons. The role of nigrastriatal tract in $\mathrm{AD}$ has been reported in studies using post-mortem brains from patient with $\mathrm{AD}$, transgenic mice with human $\mathrm{AD}$ mutations, and also from those studying the dopamine effects in $\mathrm{AD}$ (Uchihara et al., 1992; Love et al., 1996; Perez et al., 2005; Nardone et al., 2014). Diffuse plaques in the striatum and neurofibrillary tangles in the SN were consistent findings in all of the Alzheimer brains tested (Uchihara et al., 1992; Love et al., 1996). Furfuremore, a $41 \%$ significant neuronal loss was observed in SN of AD subjects compared to that in the age matched controls (Uchihara et al., 1992). Although in the study by Love et al. (1996), quantitation did not reveal a statistically significant correlation between the density of striatal plaques and the numbers of either neurofibrillary tangles or neurons in the $\mathrm{SN}$ in "pure" $\mathrm{AD}$ (i.e., without clinical or neuropathological evidence of Parkinson's or cortical Lewy body disease), the mean number of neurons in the SN of Alzheimer brains was lower than that in controls (Love et al., 1996). Pharmacologically, L-Dopa significantly increased Short-latency afferent inhibition (SAI) in the AD patients, while it failed to restore SAI abnormality in patients with Cerebral Autosomal Dominant Arteriopathy with Sub-cortical Infarcts (Nardone et al., 2014). Therefore, L-Dopa-mediated changes on SAI in $\mathrm{AD}$ patients seem to be a specific effect. The striatum and the $\mathrm{SN}$ of transgenic mice harboring familial $\mathrm{AD}$ (FAD)linked APPswe/PS1DeltaE9 mutants exhibit morphological alterations accompanied by amyloid-beta $(A \beta)$ deposition 6 months of age, and the extent of deposition increases in an age-dependent manner (Perez et al., 2005). In addition, a reduction in the dopamine metabolite DOPAC was also observed in the striatum of these mice (Perez et al., 2005). These findings suggested a close association between amyloid deposition and nigrostriatal pathology and suggest that altered familial $\mathrm{AD}$-linked amyloid metabolism impairs, at least in part, the function of dopaminergic neurons.

L-DOPA treatment and deep brain stimulation only provide symptomatic relief by increasing brain DA levels without altering the course of the disease. Scientists have been attempting to adjust the developmental course of the disease by restoring region-specific DA neuron architecture (Soderstrom et al., 2006). Initial trials to replenish DA neurons used grafts of DAproducing adult adrenomedullary tissue and then fetal mesencephalic tissue (Collier et al., 2002; Williams and Lavik, 2009; Lindvall and Kokaia, 2010), but encountered many obstacles (Björklund, 1993). Recent discoveries overcame these hurdles by generating patient-derived pluripotent and growth factorenhanced fibroblasts to increase the supply of tissue for grafting and to prevent transplant rejection. However, new problems have materialized. It is still not clear whether grafted cells will survive in a pathological environment with a deteriorated milieu and be appropriately integrated into a $>50$-year-old local neuronal network. In fact, patients in clinical trials with grafted cells emerged with dyskinesia (Freed, 2002; Maries et al., 2006). This data implicates that the grafted new cells were not integrated into the existing neuronal network and were not capable of performing the expected functions. Interestingly, PD pathological markers, Lewy bodies and $\alpha$-synuclein aggregates, had been observed in the grafted cells (Li et al., 2008; Hansen et al., 2011). Thus, there is an urgent need for a therapeutic strategy to restore functional DA neurons, which could effectively integrate into the existing neuronal network.

\section{AP $\alpha$ IMPROVES BALANCE AND COORDINATION AND INCREASES THE NUMBER OF NEW TYROSINE HYDROXYLASE CELLS IN SNpc OF MPTP-LESIONED MICE}

MPTP-lesion impairs the motor performance, particularly in the modalities of balance and coordination, in C57BL/6J mice (Antzoulatos et al., 2010). The balance and coordination of MPTP-lesioned mice were improved in a rotarod performance task in which mice were forced to move correctly to prevent them from falling. Mice that received peripheral administration of $\mathrm{AP} \alpha$ almost completely regained their ability to walk on the rod (Adeosun et al., 2012). Correlated to the improvement of motor performance, the number of tyrosine hydroxylase immunoreactive (TH-IR) cells in the SN in AP $\alpha$-treated, MPTP-lesioned mice was increased. This data suggests that $\mathrm{AP} \alpha$ promotes the reinstallation of functional neural circuits in the nigrostriatal pathway either by reversal (recovery) of the MPTP-induced degeneration of TH neurons, and/or the generation of new (or differentiated) $\mathrm{TH}$-expressing neurons in this brain region. In addition to the increase of TH-IR neurons, $\mathrm{AP} \alpha$ also increased the number of Nissl stained cells, which were both reduced in mice only received the MPTP neurotoxin. These results, in addition to the increase of BrdU/TH double positive cells in $\mathrm{AP} \alpha$-treated mice, suggest that new cells, not only TH-IR neurons but also the nonneuronal cells, were added into the SN of the MPTP-lesioned mice (Adeosun et al., 2012; Figure 1).

It is still in debate whether neurogenesis also occurs in the SN. Studies from different groups demonstrated that new cells were born in the healthy SN (Lie et al., 2002; Zhao et al., 2003). The precursor cells isolated from the SN had the ability to differentiate into neurons in vitro (Lie et al., 2002) or the generation of new mature nigral DA neurons under physiological conditions by colocalization of BrdU and TH (Zhao et al., 2003). In contrast, opposite report indicated that there is no evidence for neurogenesis in SN (Frielingsdorf et al., 2004) and argued that the BrdU and $\mathrm{TH}$ co-localization was an overlay of a BrdU positive glia on an adjacent neuron (Borta and Hoglinger, 2007). However, a number of works have also described the expression of polysialylated-neural cell adhesion molecule (PSA-NCAM), a molecular expressed in multipotent progenitor cells, in the cells of SN (Nomura et al., 2000; Yoshimi et al., 2005) and a small number of cells are PSA-NCAM double positive (Yoshimi et al., 2005). Borta and Hoglinger (2007) discussed that PSA-NCAM is also expressed in other cells undergoing plastic changes, and therefore, these results do not support the hypothesis of dopaminergic neurogenesis in the SN. Peng et al. reported that fibroblast growth 


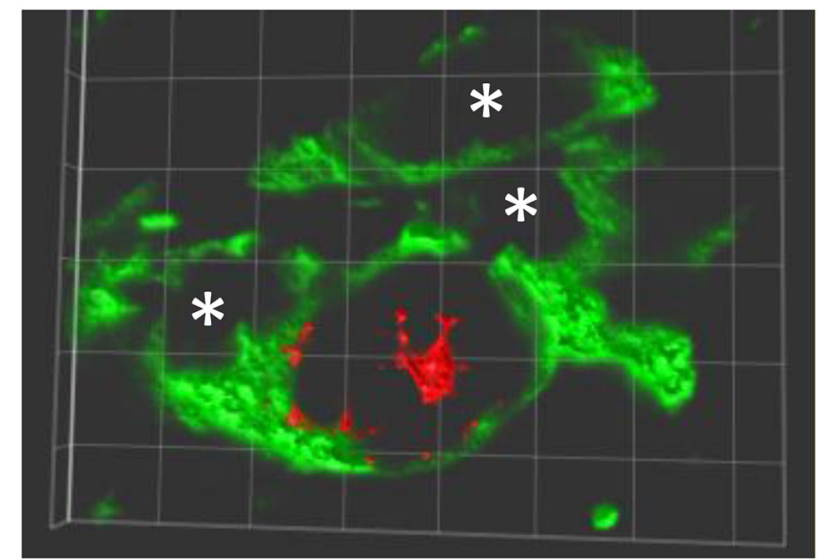

FIGURE 1 | New TH expressing neurons in SNpc of allopreganolone treated mice lesioned by MPTP. A 3-dimensionally rotated double-immunolabeling image shows a new neuron (red, BrdU positive in nuclear) expressing $\mathrm{TH}$ (green in cytoplasm and neurites), and a few $\mathrm{TH}$ positive only neurons marked with * Similar image can be found in Adeosun et al. (2012).

factor 2 increased the number of BrdU and doublecortin double positive cells in SN of MPTP-lesioned mice (Peng et al., 2008). Others reported that either physical activity or Unilateral lesion of the subthalamic nucleus increased the oligodendrogenesis and astrogliogenesis in the SN after 6-OHDA lesion (Steiner et al., 2008; Klaissle et al., 2012). Recently, it was also reported that the majority of newly generated cells in the adult mouse SN express low levels of doublecortin (Worlitzer et al., 2013). Taken together, these data support the generation of new cells in SN, but whether these new cells will differentiate into functional DA neurons is not clear. Perhaps by reestablishing the extracellular milieu and local environment in $\mathrm{SN}$ to a level suitable for new neuron differentiation, maturation and integration into the existing neuronal circuits will be a hopeful solution. In addition, appropriate labeling protocols may be needed to identify the newly generated neurons by optimized amount of BrdU (Zhao and Janson Lang, 2009), or by tracing the ratio of $C^{14}$ in DNA of cells in striatum of human brains (Ernst et al., 2014).

Accumulated evidence suggests that there are multiple neurogenic niches in the brain apart from the hippocampal dentate gyrus sub granular zone (SGZ) and the cerebral sub ventricular zone (SVZ). These include the hypothalamus (Lee et al., 2012), cerebellum (Keller et al., 2004; Ponti et al., 2005, 2006, 2008, 2010; Bonfanti and Ponti, 2008; Hajihosseini et al., 2008), striatum (Tattersfield et al., 2004; Ninomiya et al., 2006; Luzzati et al., 2007; Snyder et al., 2010; Danilov et al., 2012; Delavaran et al., 2013; Ernst et al., 2014; Kempermann, 2014), and SN (Bayer et al., 1995; Zhao et al., 2003; Chen et al., 2005; Van Kampen and Robertson, 2005; Yoshimi et al., 2005; Arias-Carrión et al., 2006, 2009; Freundlieb et al., 2006; Shan et al., 2006; Steiner et al., 2006; Esposito et al., 2007; Mandel et al., 2007; Di Giovanni et al., 2009; Ries et al., 2009; Park et al., 2012; Sun et al., 2012a,b; Worlitzer et al., 2013). Therefore, AP $\alpha$ may promote the generation of new cells locally in SN. One such possibility is that $\mathrm{AP} \alpha$ increases proliferation of glial fibrillary acidic protein (GFAP), or Ng2 expressing glia cells, which maintain their mitotic status, and drives the differentiation of these new cells into DA neurons in the SN. This hypothesis is supported by the recent studies demonstrating that the primary progenitors in adult neurogenesis are astrocyte-like cells that express GFAP and that surviving cells exhibit neurites 7 days after proliferation (Cabras et al., 2010; Ming and Song, 2011). Furthermore, it has also been reported that, in the presence of sonic hedgehog, GFAPexpressing mesencephalic progenitor cells can be differentiated into TH-IR neurons within 4 days (Matsuura et al., 2001). Parallelly, the new adult subependyma cells (BrdU positive) of the lateral ventricle can differentiate into TH-expressing neurons after 24-h exposure to fibroblast growth factor (bFGF2) and glial cell conditioned media (Daadi and Weiss, 1999). Therefore, it is possible that in the $\mathrm{SN}$, the proliferating glial-like cells have the capacity to differentiate into both neurons and glial cells as regulated by their microenvironment. This is further supported by a recent study which demonstrate that glia cells can differentiate into neurons in the presence of neuronal differentiation 1, a basic helix-loop-helix transcription factor (Guo et al., 2014).

\section{AP $\alpha$ IS A POTENTIAL NEUROGENIC AGENT IN NIGROSTRIATAL TRACT}

The neurotrophic feature of $\mathrm{AP} \alpha$ is widely supported by the literature. $\mathrm{AP} \alpha$ is produced in pluripotent progenitor cells (Lauber and Lichtensteiger, 1996; Gago et al., 2004) and neurons (Pinna et al., 2004; Agís-Balboa et al., 2006) throughout the embryonic period. In late gestation, a developing period in which large amount of CNS neurons are generated and functional circuits are formed, $\mathrm{AP} \alpha$ concentration is 20-30 times higher than any other time in life (Pomata et al., 2000). In pathological conditions, the concentration of $\mathrm{AP} \alpha$ is significantly reduced in the brains of humans with AD (Marx et al., 2006; Smith et al., 2006; Naylor et al., 2010), with PD (di Michele et al., 2003; Luchetti et al., 2010) as well as from the brains of a transgenic mouse model of $\mathrm{AD}$ (Wang et al., 2007, 2010). More interestingly, the lower the AP $\alpha$ concentration, the more severe these neurodegenerative diseases are and the pathology appears to be inversely correlated with the levels of $\mathrm{AP} \alpha$ (Naylor et al., 2010).

In mice lesioned with MPTP, $\mathrm{AP} \alpha$ reversed the cell number decline of TH-expressing and Nissl positive cells in both $\mathrm{SN}$ and Locus coeruleus (LC; Adeosun et al., 2012). This data suggest that the generation of new cells by $\mathrm{AP} \alpha$ is not cell type, brain region, or mouse model specific, as we previously reported the neurogenic property of AP $\alpha$ in the SGZ and SVZ in a mouse model of AD (Wang et al., 2010; Chen et al., 2011; Singh et al., 2012). The fact that $\mathrm{AP} \alpha$ increased the proliferation of cerebellar neurogenic cells supports the observation that $\mathrm{AP} \alpha$ is not only a neurogenic agent in known neurogenic areas such as SGZ and SVZ, but also in brain regions such as the cerebellum (Keller et al., 2004) and the SNpc (Adeosun et al., 2012; Sun et al., 2012a).

Interestingly, it appears that the neurogenic effects of AP $\alpha$ need to be enhanced or maintained with physical activities (Adeosun et al., 2012). In support, utilizing running wheels or forced 
treadmill for several weeks increased the TH expression (Gerecke et al., 2010; Tajiri et al., 2010). Moreover, a significant increase in numbers of newborn NG2-positive and GFAP-positive cells was observed in the SN of 6-OHDA lesioned animals living in enriched environment with physical activity for 7 weeks. These mice showed improved motor behavior compared to controls under standard conditions (Steiner et al., 2006). Therefore, it is likely that forced physical activity helps the survival and differentiation of newly formed cells induced by $\mathrm{AP} \alpha$. This point of view is supported by the fact that newly formed neural progenitors can differentiate into TH-expressing neurons within $24 \mathrm{~h}$ when exposed to glial cell conditioned media or basic bFGF2 (Daadi and Weiss, 1999), and in line with report that bFGF2 expression is increased after physical exercise (Gómez-Pinilla et al., 1997).

\section{AP $\alpha$ FUNCTIONS IN THE NIGROSTRIATAL TRACT OF MICE WITH AD MUTATIONS}

Is $\mathrm{AP} \alpha$ only a blockade for MPTP-lesion, or a neurogenic agent in the SN? Recent work demonstrating that $\mathrm{AP} \alpha$ also increases $\mathrm{TH}$ positive neurons and total cell numbers in the $\mathrm{SN}$ of a triple transgenic mouse for AD (3xTgAD) Sun et al. (2012a) clarified that $\mathrm{AP} \alpha$ played its role through reestablishment of DA neuronal architecture, rather than by the blockade of the neurotoxic function of MPTP. Further support is from reports that genetic risk factors found in familial AD (i.e., mutations in APP, PS1 and tau phosphorylation genes) also play a role in SNpc neuropathology and atrophy.

Besides the occurrence of plaques, tangles and hippocampal atrophy, atrophy in brain nuclei containing TH expressing neurons is also a neuropathological feature of late-onset AD (Chui et al., 1986; LaFerla et al., 1997; Zarow et al., 2003). For example, a meta-analysis concluded a consistently high $\mathrm{TH}$ neuron loss (52-76\%) in LC, and a variable neuron loss (4-50\%) in the SNpc in post-mortem brains of late onset $\mathrm{AD}$ subjects (Zarow et al., 2003). These data indicate that reduction of $\mathrm{TH}$ expressing and total neurons in SN of animals bearing AD mutations (Sun et al., 2012a) occurs, and is in agreement with those early studies from AD subjects (Zarow et al., 2003).

Supportive evidence was also emerged from the transgenic APP/PS1 mouse model of AD, in which hyper-accumulated A $\beta-42$ residues lead to the early appearance of amyloid plaque formation when compared to mice with only the single transgene APP (Perez et al., 2005; O'Neil et al., 2007). In the APP/PS1 double mutant mice there was a significant $(24 \%)$ reduction in $\mathrm{TH}$-positive neurons in the LC in comparison to their background controls (O'Neil et al., 2007). Interestingly, the loss of $\mathrm{TH}$ expressing neurons was not observed in the transgenic mouse model with APP23 (Szot et al., 2009) nor PADPP (German et al., 2005). These findings suggest that the loss of $\mathrm{TH}$ positive neurons may be a result of the double APP/PS1 mutations, rather than a single APP mutation.

It has been proposed that tau protein abnormalities play a more important role in the loss of neurons in $\mathrm{AD}$, and that deposition of amyloid plaques does not correlate well with neuron loss (Mudher and Lovestone, 2002; Mudher et al., 2004; Schmitz et al., 2004). Neurofibrillary tangle formation is composed of hyperphosphorylated microtubule-associated protein tau that appears to accumulate within vulnerable neurons and may eventually kill the cell, leaving behind only a ghost tangle and no neuron (Ramsden et al., 2005; Iqbal and Grundke-Iqbal, 2006; Gong and Iqbal, 2008). The 3xTg mice carry, in addition to two mutations in human familial $\mathrm{AD}$ genes $\left(\mathrm{APP}_{\mathrm{Swe}}, \mathrm{PS} 1_{\mathrm{M} 146 \mathrm{~V}}\right)$, one frontal temporal dementia-linked tau mutation ( $\operatorname{tau}_{\mathrm{P} 301 \mathrm{~L}}$ ) and mimic multiple aspects of $\mathrm{AD}$ neuropathology in relevant brain regions (Oddo et al., 2003a,b). The reduction of $\mathrm{TH}$ immunoreactive neurons in the $\mathrm{SNpc}$ of $3 \mathrm{xTgAD}$ male mice at 3 months old, extend the previous report and supports the hypothesis that early neurogenic deficits lead to the reduction of total neuron numbers in multiple brain regions of $\mathrm{AD}$ subjects (Wang and Sun, 2010) including SNpc. SN lesions are frequently present in $\mathrm{AD}$ and include pigmented neuronal cell loss, gliosis, Lewy bodies, $\alpha$-synuclein-stained structures, and hyperphosphorylated tau accumulation in neurofibrillary tangles as well as neuritis (Kazee et al., 1995; Klunk et al., 2004; Burns et al., 2005), suggesting that $\mathrm{AD}$ is a significant risk factor for SN lesions (Kazee et al., 1995; Kazee and Han, 1995). AP $\alpha-$ induced neurogenesis is dose-dependent and the most effective dose in vitro also has neurogenic effects in vivo that are accompanied with a reversal of the cognitive deficits in $3 x T g A D$ mice (Wang et al., 2005, 2010). Previous studies indicated biphasic dose-dependent efficacy of $\mathrm{AP} \alpha$ on neurogenesis (Wang et al., 2005, 2010). At 100, 250, and $500 \mathrm{nM}$ concentrations, $\mathrm{AP} \alpha$ significantly increased BrdU incorporation (lower concentrations were not statistically different from the control). At $1000 \mathrm{nM}$, a reversal of the dose-response was first apparent, with higher doses shifting the response to significant repression of proliferation at 100-1000 nM. A recent study titrated the optimal regimen for therapeutic efficacy of $\mathrm{AP} \alpha$ treatment in vivo in $3 \mathrm{xTgAd}$ mice (Chen et al., 2011). In both $\mathrm{AP} \alpha$ treatment regimens of a single exposure of $1 /$ month and of repeated expose (1/week/6 months), $\mathrm{AP} \alpha$ treatment significantly increased the survival of cells that were generated at the first exposure to $\mathrm{AP} \alpha$. The repeated exposure (1/week/6 months) $\mathrm{AP} \alpha$ treatment regimen had greater regenerative efficacy. However, the $3 /$ week/3 months regimen significantly reduced regenerative efficacy (Chen et al., 2011). This once per week regimen suggested there might be a 7-day cycle which could help reach the best effects of $\mathrm{AP} \alpha$ and this seems consistent with the role of AP $\alpha$ in SN (Adeosun et al., 2012; Sun et al., 2012a).

In contrast, recent work by Bengtsson and colleagues demonstrated that constant infusion of $\mathrm{AP} \alpha$ (via ALZET mini-pumps) for 3 months increase GABAergic function/inhibition in brain. These levels of $\mathrm{AP} \alpha$ showed a negative impact on both learning and memory and neuropathology of amyloid beta deposition (Bengtsson et al., 2012, 2013; Wang, 2013). Results of these investigations are in line with learning and memory deficits experienced by people who are chronically treated with high levels of anti-seizure medications. Mechanistically, this may be due to the accumulation of $\mathrm{AP} \alpha$ in the brain with a final concentration high enough to enter the second phase (inhibition) of the dose response of $\mathrm{AP} \alpha$ on neurogenesis (Wang et al., 2005; Brinton, 2013; Irwin and Brinton, 2014). 
Wang and Brinton reported that $\mathrm{AP} \alpha$ transiently increases intracellular calcium concentration in primary cultured hippocampal neurons. This intracellular calcium increase is mediated by $\mathrm{GABA}_{\mathrm{A}}$ receptor and L-type Calcium Channel (Wang and Brinton, 2008) and this calcium increase is related to neural progenitor cell proliferation in vitro (Wang et al., 2005) and in vivo (Wang et al., 2010). The $\mathrm{AP} \alpha$ induced transient increase of intracellular calcium concentration and the subsequent proliferation of progenitor cells was abolished by inhibitors for $\mathrm{GABA}_{\mathrm{A}}$ receptor and voltage gated calcium channel blockers (Wang and Brinton, 2008). Therefore, it is likely the effects of AP $\alpha$ on the increase of new neurons and cells are also mediated by $\mathrm{GABA}_{\mathrm{A}}$ receptor regulated transient increase of calcium concentration, however, more experimental evidence is needed.

\section{SUMMARY AND POTENTIAL EXPECTATION}

In summary, research demonstrates that the levels of $\mathrm{AP} \alpha$, are reduced in the brains of subjects with $\mathrm{AD}$ or $\mathrm{PD}$. The promising role of this $\mathrm{AP} \alpha$ therapy in $\mathrm{AD}$ and $\mathrm{PD}$ is supported by the recent work that peripheral administration of $\mathrm{AP} \alpha$, with its ability to permeate the blood brain barrier, could improve cognitive and motor performance and increase the number of DA neurons in the SN of mice lesioned by MPTP and mice with AD mutations. These results support that AP $\alpha$ accomplishes its role through the reestablishment of dopamine neuronal architecture, rather than blockading the neurotoxic effects of MPTP.

\section{REFERENCES}

Adeosun, S. O., Hou, X., Jiao, Y., Zheng, B., Henry, S., Hill, R., et al. (2012). Allopregnanolone reinstates tyrosine hydroxylase immunoreactive neurons and motor performance in an MPTP-lesioned mouse model of Parkinson's disease. PLoS One 7:e50040. doi: 10.1371/journal.pone.005 0040

Agís-Balboa, R. C., Pinna, G., Zhubi, A., Maloku, E., Veldic, M., Costa, E., et al. (2006). Characterization of brain neurons that express enzymes mediating neurosteroid biosynthesis. Proc. Natl. Acad. Sci. US A 103, 14602-14607. doi: 10. 1073/pnas.0606544103

Antzoulatos, E., Jakowec, M. W., Petzinger, G. M., and Wood, R. I. (2010). Sex differences in motor behavior in the MPTP mouse model of Parkinson's disease. Pharmacol. Biochem. Behav. 95, 466-472. doi: 10.1016/j.pbb.2010. 03.009

Arias-Carrión, O., Hernandez-Lopez, S., Ibanez-Sandoval, O., Bargas, J., Hernandez-Cruz, A., and Drucker-Colin, R. (2006). Neuronal precursors within the adult rat subventricular zone differentiate into dopaminergic neurons after substantia nigra lesion and chromaffin cell transplant. J. Neurosci. Res. 84, 14251437. doi: 10.1002/jnr.21068

Arias-Carrión, O., Yamada, E., Freundlieb, N., Djufri, M., Maurer, L., Hermanns, G., et al. (2009). Neurogenesis in substantia nigra of parkinsonian brains? J. Neural Transm. Suppl. 73, 279-285.

Bayer, S. A., Wills, K. V., Triarhou, L. C., Verina, T., Thomas, J. D., Ghetti, B., et al. (1995). Selective vulnerability of late-generated dopaminergic neurons of the substantia nigra in weaver mutant mice. Proc. Natl. Acad. Sci. U S A 92, 91379140. doi: 10.1073/pnas.92.20.9137

Bengtsson, S. K., Johansson, M., Backstrom, T., Nitsch, R. M., and Wang, M. (2013). Brief but chronic increase in allopregnanolone cause accelerated AD pathology differently in two mouse models. Curr. Alzheimer Res. 10, 38-47. doi: 10.2174/1567205011310010006

Bengtsson, S. K., Johansson, M., Backstrom, T., and Wang, M. (2012). Chronic allopregnanolone treatment accelerates Alzheimer's disease development in A $\beta P P($ Swe $)$ PSEN1( $\triangle E$ 9) mice. J. Alzheimers Dis. 31, 71-84. doi: 10.3233/JAD2012-120268

Björklund, A. (1993). Neurobiology. Better cells for brain repair. Nature 362, 414415. doi: $10.1038 / 362414 \mathrm{a} 0$
Bonfanti, L., and Ponti, G. (2008). Adult mammalian neurogenesis and the New Zealand white rabbit. Vet. J. 175, 310-331. doi: 10.1016/j.tvjl.2007.01.023

Borta, A., and Hoglinger, G. U. (2007). Dopamine and adult neurogenesis. J. Neurochem. 100, 587-595. doi: 10.1111/j.1471-4159.2006.04241.x

Brinton, R. D. (2013). Neurosteroids as regenerative agents in the brain: therapeutic implications. Nat. Rev. Endocrinol. 9, 241-250. doi: 10.1038/nrendo. 2013.31

Burns, J. M., Galvin, J. E., Roe, C. M., Morris, J. C., and McKeel, D. W. (2005). The pathology of the substantia nigra in Alzheimer disease with extrapyramidal signs. Neurology 64, 1397-1403. doi: 10.1212/01.wnl.0000158423.05 $224.7 \mathrm{f}$

Cabras, S., Saba, F., Reali, C., Scorciapino, M. L., Sirigu, A., Talani, G., et al. (2010). Antidepressant imipramine induces human astrocytes to differentiate into cells with neuronal phenotype. Int. J. Neuropsychopharmacol. 13, 603-615. doi: 10. 1017/s1461145710000210

Charalampopoulos, I., Remboutsika, E., Margioris, A. N., and Gravanis, A. (2008). Neurosteroids as modulators of neurogenesis and neuronal survival. Trends Endocrinol. Metab. 19, 300-307. doi: 10.1016/j.tem.2008.07.004

Chen, Y., Ai, Y., Slevin, J. R., Maley, B. E., and Gash, D. M. (2005). Progenitor proliferation in the adult hippocampus and substantia nigra induced by glial cell line-derived neurotrophic factor. Exp. Neurol. 196, 87-95. doi: 10.1016/j. expneurol.2005.07.010

Chen, S., Wang, J. M., Irwin, R. W., Yao, J., Liu, L., and Brinton, R. D. (2011). Allopregnanolone promotes regeneration and reduces $\beta$-amyloid burden in a preclinical model of Alzheimer's disease. PLoS One 6:e24293. doi: 10.1371/journal. pone.0024293

Chui, H. C., Mortimer, J. A., Slager, U., Zarow, C., Bondareff, W., and Webster, D. D. (1986). Pathologic correlates of dementia in Parkinson's disease. Arch. Neurol. 43, 991-995. doi: 10.1001/archneur.1986.00520100013007

Collier, T. J., Sortwell, C. E., Elsworth, J. D., Taylor, J. R., Roth, R. H., Sladek, J. R., et al. (2002). Embryonic ventral mesencephalic grafts to the substantia nigra of MPTP-treated monkeys: feasibility relevant to multiple-target grafting as a therapy for Parkinson's disease. J. Comp. Neurol. 442, 320-330. doi: 10.1002/cne. 10108

Daadi, M. M., and Weiss, S. (1999). Generation of tyrosine hydroxylase-producing neurons from precursors of the embryonic and adult forebrain. J. Neurosci. 19, 4484-4497.

Danilov, A. I., Kokaia, Z., and Lindvall, O. (2012). Ectopic ependymal cells in striatum accompany neurogenesis in a rat model of stroke. Neuroscience 214, 159-170. doi: 10.1016/j.neuroscience.2012.03.062

Delavaran, H., Sjunnesson, H., Arvidsson, A., Lindvall, O., Norrving, B., van Westen, D., et al. (2013). Proximity of brain infarcts to regions of endogenous neurogenesis and involvement of striatum in ischaemic stroke. Eur. J. Neurol. 20, 473-479. doi: 10.1111/j.1468-1331.2012.03877.x

Di Giovanni, G., Di Matteo, V., and Esposito, E. (2009). Birth, life and death of dopaminergic neurons in the substantia nigra. J. Neural Transm. Suppl. 73, 1, preceeding table of contents.

di Michele, F., Longone, P., Romeo, E., Lucchetti, S., Brusa, L., Pierantozzi, M., et al. (2003). Decreased plasma and cerebrospinal fluid content of neuroactive steroids in Parkinson's disease. Neurol. Sci. 24, 172-173. doi: 10.1007/s10072003-0115-1

Ernst, A., Alkass, K., Bernard, S., Salehpour, M., Perl, S., Tisdale, J., et al. (2014). Neurogenesis in the striatum of the adult human brain. Cell 156, 1072-1083. doi: 10.1016/j.cell.2014.01.044

Esposito, E., Di Matteo, V., and Di Giovanni, G. (2007). Death in the substantia nigra: a motor tragedy. Expert Rev. Neurother. 7, 677-697. doi: 10. 1586/14737175.7.6.677

Evans, J., Sun, Y., McGregor, A., and Connor, B. (2012). Allopregnanolone regulates neurogenesis and depressive/anxiety-like behaviour in a social isolation rodent model of chronic stress. Neuropharmacology 63, 1315-1326. doi: 10.1016/j. neuropharm.2012.08.012

Freed, C. R. (2002). Will embryonic stem cells be a useful source of dopamine neurons for transplant into patients with Parkinson's disease? Proc. Natl. Acad. Sci. U S A 99, 1755-1757. doi: 10.1073/pnas.062039699

Freundlieb, N., Francois, C., Tande, D., Oertel, W. H., Hirsch, E. C., and Hoglinger, G. U. (2006). Dopaminergic substantia nigra neurons project topographically organized to the subventricular zone and stimulate precursor cell proliferation in aged primates. J. Neurosci. 26, 2321-2325. doi: 10.1523/jneurosci.4859-05. 2006 
Frielingsdorf, H., Schwarz, K., Brundin, P., and Mohapel, P. (2004). No evidence for new dopaminergic neurons in the adult mammalian substantia nigra. Proc. Natl. Acad. Sci. U S A 101, 10177-10182. doi: 10.1073/pnas.0401229101

Gago, N., El-Etr, M., Sananes, N., Cadepond, F., Samuel, D., Avellana-Adalid, V., et al. (2004). 3alpha,5alpha-Tetrahydroprogesterone (allopregnanolone) and gamma-aminobutyric acid: autocrine/paracrine interactions in the control of neonatal PSA-NCAM+ progenitor proliferation. J. Neurosci. Res. 78, 770-783. doi: 10.1002/jnr.20348

Gerecke, K. M., Jiao, Y., Pani, A., Pagala, V., and Smeyne, R. J. (2010). Exercise protects against MPTP-induced neurotoxicity in mice. Brain Res. 1341, 72-83. doi: 10.1016/j.brainres.2010.01.053

German, D. C., Nelson, O., Liang, F., Liang, C. L., and Games, D. (2005). The PDAPP mouse model of Alzheimer's disease: locus coeruleus neuronal shrinkage. J. Comp. Neurol. 492, 469-476. doi: 10.1002/cne.20744

Gómez-Pinilla, F., Dao, L., and So, V. (1997). Physical exercise induces FGF-2 and its mRNA in the hippocampus. Brain Res. 764, 1-8. doi: 10.1016/s00068993(97)00375-2

Gong, C. X., and Iqbal, K. (2008). Hyperphosphorylation of microtubuleassociated protein tau: a promising therapeutic target for Alzheimer disease. Curr. Med. Chem. 15, 2321-2328. doi: 10.2174/092986708785909111

Guo, Z., Zhang, L., Wu, Z., Chen, Y., Wang, F., and Chen, G. (2014). In vivo direct reprogramming of reactive glial cells into functional neurons after brain injury and in an Alzheimer's disease model. Cell Stem Cell 14, 188-202. doi: 10.1016/j. stem.2013.12.001

Hajihosseini, M. K., De Langhe, S., Lana-Elola, E., Morrison, H., Sparshott, N., Kelly, R., et al. (2008). Localization and fate of Fgf10-expressing cells in the adult mouse brain implicate Fgf10 in control of neurogenesis. Mol. Cell. Neurosci. 37, 857-868. doi: 10.1016/j.mcn.2008.01.008

Hansen, C., Angot, E., Bergstrom, A. L., Steiner, J. A., Pieri, L., Paul, G., et al. (2011). $\alpha$-Synuclein propagates from mouse brain to grafted dopaminergic neurons and seeds aggregation in cultured human cells. J. Clin. Invest. 121, 715-725. doi: 10. 1172/JCI43366

Hellgren, C., Akerud, H., Skalkidou, A., Backstrom, T., and Sundstrom-Poromaa, I. (2014). Low serum allopregnanolone is associated with symptoms of depression in late pregnancy. Neuropsychobiology 69, 147-153. doi: 10.1159/000358838

Iqbal, K., and Grundke-Iqbal, I. (2006). Discoveries of tau, abnormally hyperphosphorylated tau and others of neurofibrillary degeneration: a personal historical perspective. J. Alzheimers Dis. 9(3 Suppl.), 219-242.

Irwin, R. W., and Brinton, R. D. (2014). Allopregnanolone as regenerative therapeutic for Alzheimer's disease: translational development and clinical promise. Prog. Neurobiol. 113, 40-55. doi: 10.1016/j.pneurobio.2013.08.004

Kazee, A. M., Cox, C., and Richfield, E. K. (1995). Substantia nigra lesions in Alzheimer disease and normal aging. Alzheimer Dis. Assoc. Disord. 9, 61-67. doi: 10.1097/00002093-199509020-00001

Kazee, A. M., and Han, L. Y. (1995). Cortical Lewy bodies in Alzheimer's disease. Arch. Pathol. Lab. Med. 119, 448-453.

Keller, E. A., Zamparini, A., Borodinsky, L. N., Gravielle, M. C., and Fiszman, M. L. (2004). Role of allopregnanolone on cerebellar granule cells neurogenesis. Brain Res. Dev. Brain Res. 153, 13-17. doi: 10.1016/j.devbrainres.2004.07.009

Kempermann, G. (2014). Off the beaten track: new neurons in the adult human striatum. Cell 156, 870-871. doi: 10.1016/j.cell.2014.02.027

Klaissle, P., Lesemann, A., Huehnchen, P., Hermann, A., Storch, A., and Steiner, B. (2012). Physical activity and environmental enrichment regulate the generation of neural precursors in the adult mouse substantia nigra in a dopamine-dependent manner. BMC Neurosci. 13:132. doi: 10.1186/1471-220213-132

Klunk, W. E., Engler, H., Nordberg, A., Wang, Y., Blomqvist, G., Holt, D. P., et al. (2004). Imaging brain amyloid in Alzheimer's disease with Pittsburgh Compound-B. Ann. Neurol. 55, 306-319. doi: 10.1002/ana.20009

LaFerla, F. M., Troncoso, J. C., Strickland, D. K., Kawas, C. H., and Jay, G. (1997). Neuronal cell death in Alzheimer's disease correlates with apoE uptake and intracellular Abeta stabilization. J. Clin. Invest. 100, 310-320. doi: 10. $1172 /$ jci1 19536

Lauber, M. E., and Lichtensteiger, W. (1996). Ontogeny of 5 alpha-reductase (type 1) messenger ribonucleic acid expression in rat brain: early presence in germinal zones. Endocrinology 137, 2718-2730. doi: 10.1210/en.137.7.2718

Lee, D. A., Bedont, J. L., Pak, T., Wang, H., Song, J., Miranda-Angulo, A., et al. (2012). Tanycytes of the hypothalamic median eminence form a diet-responsive neurogenic niche. Nat. Neurosci. 15, 700-702. doi: 10.1038/nn.3079
Li, J. Y., Englund, E., Holton, J. L., Soulet, D., Hagell, P., Lees, A. J., et al. (2008). Lewy bodies in grafted neurons in subjects with Parkinson's disease suggest hostto-graft disease propagation. Nat. Med. 14, 501-503. doi: 10.1038/nm1746

Lie, D. C., Dziewczapolski, G., Willhoite, A. R., Kaspar, B. K., Shults, C. W., and Gage, F. H. (2002). The adult substantia nigra contains progenitor cells with neurogenic potential. J. Neurosci. 22, 6639-6649.

Lindvall, O., and Kokaia, Z. (2010). Stem cells in human neurodegenerative disorders-time for clinical translation? J. Clin. Invest. 120, 29-40. doi: 10. 1172/JCI40543

Love, S., Wilcock, G. K., and Matthews, S. M. (1996). No correlation between nigral degeneration and striatal plaques in Alzheimer's disease. Acta Neuropathol. 91, 432-436. doi: 10.1007/s004010050447

Luchetti, S., Bossers, K., Frajese, G. V., and Swaab, D. F. (2010). Neurosteroid biosynthetic pathway changes in substantia nigra and caudate nucleus in Parkinson's disease. Brain Pathol. 20, 945-951. doi: 10.1111/j.1750-3639.2010. 00396.x

Luzzati, F., De Marchis, S., Fasolo, A., and Peretto, P. (2007). Adult neurogenesis and local neuronal progenitors in the striatum. Neurodegener. Dis. 4, 322-327. doi: 10.1159/000101889

Mandel, S. A., Sagi, Y., and Amit, T. (2007). Rasagiline promotes regeneration of substantia nigra dopaminergic neurons in post-MPTP-induced Parkinsonism via activation of tyrosine kinase receptor signaling pathway. Neurochem. Res. 32, 1694-1699. doi: 10.1007/s11064-007-9351-8

Maries, E., Kordower, J. H., Chu, Y., Collier, T. J., Sortwell, C. E., Olaru, E., et al. (2006). Focal not widespread grafts induce novel dyskinetic behavior in parkinsonian rats. Neurobiol. Dis. 21, 165-180. doi: 10.1016/j.nbd.2005. 07.002

Marx, C. E., Trost, W. T., Shampine, L. J., Stevens, R. D., Hulette, C. M., Steffens, D. C., et al. (2006). The neurosteroid allopregnanolone is reduced in prefrontal cortex in Alzheimer's disease. Biol. Psychiatry 60, 1287-1294. doi: 10.1016/j. biopsych.2006.06.017

Matsuura, N., Lie, D. C., Hoshimaru, M., Asahi, M., Hojo, M., Ishizaki, R., et al. (2001). Sonic hedgehog facilitates dopamine differentiation in the presence of a mesencephalic glial cell line. J. Neurosci. 21, 4326-4335.

Ming, G. L., and Song, H. (2011). Adult neurogenesis in the mammalian brain: significant answers and significant questions. Neuron 70, 687-702. doi: 10 . 1016/j.neuron.2011.05.001

Mudher, A., and Lovestone, S. (2002). Alzheimer's disease-do tauists and baptists finally shake hands? Trends Neurosci. 25, 22-26. doi: 10.1016/s01662236(00)02031-2

Mudher, A., Shepherd, D., Newman, T. A., Mildren, P., Jukes, J. P., Squire, A., et al. (2004). GSK-3beta inhibition reverses axonal transport defects and behavioural phenotypes in Drosophila. Mol. Psychiatry 9, 522-530. doi: 10.1038/sj.mp. 4001483

Nardone, R., Holler, Y., Thomschewski, A., Kunz, A. B., Lochner, P., Golaszewski, S., et al. (2014). Dopamine differently modulates central cholinergic circuits in patients with Alzheimer disease and CADASIL. J. Neural Transm. doi: 10. 1007/s00702-014-1195-1. [Epub ahead of print].

Naylor, J. C., Kilts, J. D., Hulette, C. M., Steffens, D. C., Blazer, D. G., Ervin, J. F., et al. (2010). Allopregnanolone levels are reduced in temporal cortex in patients with Alzheimer's disease compared to cognitively intact control subjects. Biochim. Biophys. Acta 1801, 951-959. doi: 10.1016/j.bbalip.2010. 05.006

Ninomiya, M., Yamashita, T., Araki, N., Okano, H., and Sawamoto, K. (2006). Enhanced neurogenesis in the ischemic striatum following EGF-induced expansion of transit-amplifying cells in the subventricular zone. Neurosci. Lett. 403, 63-67. doi: 10.1016/j.neulet.2006.04.039

Nomura, T., Yabe, T., Rosenthal, E. S., Krzan, M., and Schwartz, J. P. (2000). PSANCAM distinguishes reactive astrocytes in 6-OHDA-lesioned substantia nigra from those in the striatal terminal fields. J. Neurosci. Res. 61, 588-596. doi: 10. 1002/1097-4547(20000915)61:6<588::aid-jnr2>3.3.co;2-d

Oddo, S., Caccamo, A., Kitazawa, M., Tseng, B. P., and LaFerla, F. M. (2003a). Amyloid deposition precedes tangle formation in a triple transgenic model of Alzheimer's disease. Neurobiol. Aging 24, 1063-1070. doi: 10.1016/j. neurobiolaging.2003.08.012

Oddo, S., Caccamo, A., Shepherd, J. D., Murphy, M. P., Golde, T. E., Kayed, R., et al. (2003b). Triple-transgenic model of Alzheimer's disease with plaques and tangles: intracellular Abeta and synaptic dysfunction. Neuron 39, 409-421. doi: 10.1016/s0896-6273(03)00434-3 
O’Neil, J. N., Mouton, P. R., Tizabi, Y., Ottinger, M. A., Lei, D. L., Ingram, D. K., et al. (2007). Catecholaminergic neuronal loss in locus coeruleus of aged female dtg APP/PS1 mice. J. Chem. Neuroanat. 34, 102-107. doi: 10.1016/j.jchemneu. 2007.05.008

Park, H. J., Shin, J. Y., Lee, B. R., Kim, H. O., and Lee, P. H. (2012). Mesenchymal stem cells augment neurogenesis in the subventricular zone and enhance differentiation of neural precursor cells into dopaminergic neurons in the substantia nigra of a parkinsonian model. Cell Transplant. 21, 1629-1640. doi: 10.3727/096368912x640556

Peng, J., Xie, L., Jin, K., Greenberg, D. A., and Andersen, J. K. (2008). Fibroblast growth factor 2 enhances striatal and nigral neurogenesis in the acute 1-methyl4-phenyl-1,2,3,6-tetrahydropyridine model of Parkinson's disease. Neuroscience 153, 664-670. doi: 10.1016/j.neuroscience.2008.02.063

Perez, S. E., Lazarov, O., Koprich, J. B., Chen, E. Y., Rodriguez-Menendez, V., Lipton, J. W., et al. (2005). Nigrostriatal dysfunction in familial Alzheimer's disease-linked APPswe/PS1DeltaE9 transgenic mice. J. Neurosci. 25, 10220 10229. doi: 10.1523/jneurosci.2773-05.2005

Pinna, G., Agis-Balboa, R. C., Doueiri, M. S., Guidotti, A., and Costa, E. (2004). Brain neurosteroids in gender-related aggression induced by social isolation. Crit. Rev. Neurobiol. 16, 75-82. doi: 10.1615/critrevneurobiol.v16. i12.80

Pomata, P. E., Colman-Lerner, A. A., Baranao, J. L., and Fiszman, M. L. (2000). In vivo evidences of early neurosteroid synthesis in the developing rat central nervous system and placenta. Brain Res. Dev. Brain Res. 120, 83-86. doi: 10. 1016/s0165-3806(99)00181-9

Ponti, G., Conti, L., Cataudella, T., Zuccato, C., Magrassi, L., Rossi, F., et al. (2005). Comparative expression profiles of ShcB and ShcC phosphotyrosine adapter molecules in the adult brain. Neuroscience 133, 105-115. doi: 10.1016/j. neuroscience.2005.02.014

Ponti, G., Crociara, P., Armentano, M., and Bonfanti, L. (2010). Adult neurogenesis without germinal layers: the "atypical" cerebellum of rabbits. Arch. Ital. Biol. $148,147-158$.

Ponti, G., Peretto, P., and Bonfanti, L. (2006). A subpial, transitory germinal zone forms chains of neuronal precursors in the rabbit cerebellum. Dev. Biol. 294, 168-180. doi: 10.1016/j.ydbio.2006.02.037

Ponti, G., Peretto, P., and Bonfanti, L. (2008). Genesis of neuronal and glial progenitors in the cerebellar cortex of peripuberal and adult rabbits. PLoS One 3:e2366. doi: 10.1371/journal.pone.0002366

Ramsden, M., Kotilinek, L., Forster, C., Paulson, J., McGowan, E., SantaCruz, K., et al. (2005). Age-dependent neurofibrillary tangle formation, neuron loss and memory impairment in a mouse model of human tauopathy (P301L). J. Neurosci. 25, 10637-10647. doi: 10.1523/jneurosci.3279-05.2005

Ries, V., Cheng, H. C., Baohan, A., Kareva, T., Oo, T. F., Rzhetskaya, M., et al. (2009). Regulation of the postnatal development of dopamine neurons of the substantia nigra in vivo by Akt/protein kinase B. J. Neurochem. 110, 23-33. doi: 10.1111/j. 1471-4159.2009.06101.x

Schmitz, C., Rutten, B. P., Pielen, A., Schafer, S., Wirths, O., Tremp, G., et al. (2004). Hippocampal neuron loss exceeds amyloid plaque load in a transgenic mouse model of Alzheimer's disease. Am. J. Pathol. 164, 1495-1502. doi: 10.1016/s00029440(10)63235-x

Schüle, C., Eser, D., Baghai, T. C., Nothdurfter, C., Kessler, J. S., and Rupprecht, R. (2011). Neuroactive steroids in affective disorders: target for novel antidepressant or anxiolytic drugs? Neuroscience 191, 55-77. doi: 10.1016/j.neuroscience. 2011.03.025

Schüle, C., Nothdurfter, C., and Rupprecht, R. (2014). The role of allopregnanolone in depression and anxiety. Prog. Neurobiol. 113, 79-87. doi: 10.1016/j.pneurobio. 2013.09.003

Shan, X., Chi, L., Bishop, M., Luo, C., Lien, L., Zhang, Z., et al. (2006). Enhanced de novo neurogenesis and dopaminergic neurogenesis in the substantia nigra of 1-methyl-4-phenyl-1,2,3,6-tetrahydropyridine-induced Parkinson's disease-like mice. Stem Cells 24, 1280-1287. doi: 10.1634/stemcells.2005-0487

Singh, C., Liu, L., Wang, J. M., Irwin, R. W., Yao, J., Chen, S., et al. (2012). Allopregnanolone restores hippocampal-dependent learning and memory and neural progenitor survival in aging 3xTgAD and nonTg mice. Neurobiol. Aging 33, 1493-1506. doi: 10.1016/j.neurobiolaging.2011.06.008

Smith, C. D., Wekstein, D. R., Markesbery, W. R., and Frye, C. A. (2006). 3alpha,5alpha-THP: a potential plasma neurosteroid biomarker in Alzheimer's disease and perhaps non-Alzheimer's dementia. Psychopharmacology (Berl) 186, 481-485. doi: 10.1007/s00213-005-0186-1
Snyder, B. R., Chiu, A. M., Prockop, D. J., and Chan, A. W. (2010). Human multipotent stromal cells (MSCs) increase neurogenesis and decrease atrophy of the striatum in a transgenic mouse model for Huntington's disease. PLoS One 5:e9347. doi: 10.1371/journal.pone.0009347

Soderstrom, K., O’Malley, J., Steece-Collier, K., and Kordower, J. H. (2006). Neural repair strategies for Parkinson's disease: insights from primate models. Cell Transplant. 15, 251-265. doi: 10.3727/0000000067839 82025

Steiner, B., Kupsch, A., Siebert, E., Hosmann, K., Klempin, F., Morgenstern, R., et al. (2008). Unilateral lesion of the subthalamic nucleus transiently provokes bilateral subacute glial cell proliferation in the adult rat substantia nigra. Neurosci. Lett. 430, 103-108. doi: 10.1016/j.neulet.2007. 10.045

Steiner, B., Winter, C., Hosman, K., Siebert, E., Kempermann, G., Petrus, D. S., et al. (2006). Enriched environment induces cellular plasticity in the adult substantia nigra and improves motor behavior function in the 6-OHDA rat model of Parkinson's disease. Exp. Neurol. 199, 291-300. doi: 10.1016/j.expneurol.2005. 11.004

Sun, C., Ou, X., Farley, J. M., Stockmeier, C., Bigler, S., Brinton, R. D., et al. (2012a). Allopregnanolone increases the number of dopaminergic neurons in substantia nigra of a triple transgenic mouse model of Alzheimer's disease. Curr. Alzheimer Res. 9, 473-480. doi: 10.2174/156720512800492567

Sun, X., Zhang, Q. W., Xu, M., Guo, J. J., Shen, S. W., Wang, Y. Q., et al. (2012b). New striatal neurons form projections to substantia nigra in adult rat brain after stroke. Neurobiol. Dis. 45, 601-609. doi: 10.1016/j.nbd.2011. 09.018

Szot, P., Van Dam, D., White, S. S., Franklin, A., Staufenbiel, M., and De Deyn, P. P. (2009). Age-dependent changes in noradrenergic locus coeruleus system in wild-type and APP23 transgenic mice. Neurosci. Lett. 463, 93-97. doi: 10.1016/j. neulet.2009.07.055

Tajiri, N., Yasuhara, T., Shingo, T., Kondo, A., Yuan, W., Kadota, T., et al. (2010). Exercise exerts neuroprotective effects on Parkinson's disease model of rats. Brain Res. 1310, 200-207. doi: 10.1016/j.brainres.2009. 10.075

Tattersfield, A. S., Croon, R. J., Liu, Y. W., Kells, A. P., Faull, R. L., and Connor, B. (2004). Neurogenesis in the striatum of the quinolinic acid lesion model of Huntington's disease. Neuroscience 127, 319-332. doi: 10.1016/j.neuroscience. 2004.04.061

Uchihara, T., Kondo, H., Kosaka, K., and Tsukagoshi, H. (1992). Selective loss of nigral neurons in Alzheimer's disease: a morphometric study. Acta Neuropathol. 83, 271-276. doi: 10.1007/bf00296789

Van Kampen, J. M., and Robertson, H. A. (2005). A possible role for dopamine D3 receptor stimulation in the induction of neurogenesis in the adult rat substantia nigra. Neuroscience 136, 381-386. doi: 10.1016/j.neuroscience.2005. 07.054

Wang, M. (2013). Neurosteroids and brain aging. Minerva Ginecol. 65, 587-605.

Wang, J. M., and Brinton, R. D. (2008). Allopregnanolone-induced rise in intracellular calcium in embryonic hippocampal neurons parallels their proliferative potential. BMC Neurosci. 9(Suppl. 2):S11. doi: 10.1186/1471-2202-9s2-s11

Wang, J. M., Irwin, R. W., Liu, L., Chen, S., and Brinton, R. D. (2007). Regeneration in a degenerating brain: potential of allopregnanolone as a neuroregenerative agent. Curr. Alzheimer Res. 4, 510-517. doi: 10.2174/156720507783 018262

Wang, J. M., Johnston, P. B., Ball, B. G., and Brinton, R. D. (2005). The neurosteroid allopregnanolone promotes proliferation of rodent and human neural progenitor cells and regulates cell-cycle gene and protein expression. J. Neurosci. 25, 4706-4718. doi: 10.1523/jneurosci.4520-04.2005

Wang, J. M., Singh, C., Liu, L., Irwin, R. W., Chen, S., Chung, E. J., et al. (2010). Allopregnanolone reverses neurogenic and cognitive deficits in mouse model of Alzheimer's disease. Proc. Natl. Acad. Sci. U S A 107, 6498-6503. doi: 10. 1073/pnas. 1001422107

Wang, J. M., and Sun, C. (2010). Calcium and neurogenesis in Alzheimer's disease. Front. Neurosci. 4:194. doi: 10.3389/fnins.2010.00194

Williams, C. A., and Lavik, E. B. (2009). Engineering the CNS stem cell microenvironment. Regen. Med. 4, 865-877. doi: 10.2217/rme. 09.62

Worlitzer, M. M., Viel, T., Jacobs, A. H., and Schwamborn, J. C. (2013). The majority of newly generated cells in the adult mouse substantia nigra express low 
levels of Doublecortin, but their proliferation is unaffected by 6-OHDA-induced nigral lesion or Minocycline-mediated inhibition of neuroinflammation. Eur. J. Neurosci. 38, 2684-2692. doi: 10.1111/ejn.12269

Yoshimi, K., Ren, Y. R., Seki, T., Yamada, M., Ooizumi, H., Onodera, M., et al. (2005). Possibility for neurogenesis in substantia nigra of parkinsonian brain. Ann. Neurol. 58, 31-40. doi: 10.1002/ana.20506

Zarow, C., Lyness, S. A., Mortimer, J. A., and Chui, H. C. (2003). Neuronal loss is greater in the locus coeruleus than nucleus basalis and substantia nigra in Alzheimer and Parkinson diseases. Arch. Neurol. 60, 337-341. doi: 10. 1001/archneur.60.3.337

Zhao, M., and Janson Lang, A. M. (2009). Bromodeoxyuridine infused into the cerebral ventricle of adult mice labels nigral neurons under physiological conditions-a method to detect newborn nerve cells in regions with a low rate of neurogenesis. J. Neurosci. Methods 184, 327-331. doi: 10.1016/j.jneumeth.2009. 08.007

Zhao, M., Momma, S., Delfani, K., Carlen, M., Cassidy, R. M., Johansson, C. B., et al. (2003). Evidence for neurogenesis in the adult mammalian substantia nigra. Proc. Natl. Acad. Sci. U S A 100, 7925-7930. doi: 10.1073/pnas.1131 955100

Conflict of Interest Statement: The author declares that the research was conducted in the absence of any commercial or financial relationships that could be construed as a potential conflict of interest.

Received: 30 March 2014; accepted: 21 July 2014; published online: 12 August 2014. Citation: Wang JM (2014) Allopregnanolone and neurogenesis in the nigrostriatal tract. Front. Cell. Neurosci. 8:224. doi: 10.3389/fncel.2014.00224

This article was submitted to the journal Frontiers in Cellular Neuroscience. Copyright (c) 2014 Wang. This is an open-access article distributed under the terms of the Creative Commons Attribution License (CC BY). The use, distribution or reproduction in other forums is permitted, provided the original author(s) or licensor are credited and that the original publication in this journal is cited, in accordance with accepted academic practice. No use, distribution or reproduction is permitted which does not comply with these terms. 